\title{
Exergy Analysis of Combined Effect of Evaporative Cooling and Steam Injection on Gas Turbines Performance Enhancement in Hot and Humid Climates
}

\author{
Majed Alhazmy $^{1}$, Badr Habeebullah ${ }^{1}$, Ahmad Bokhary ${ }^{1}$, Rahim Jassim ${ }^{2}$ \\ ${ }^{1}$ Mechanical Engineering, King Abdulaziz University, Jeddah, Saudi Arabia \\ ${ }^{2}$ Technical Department, Saudi Electric Services Polytechnic (SESP), Baish, Saudi Arabia
}

\section{Email address:}

mhazmy@kau.edu.sa (M. Alhazmy), bhabeeb@kau.edu.sa (B. Habeebullah), abokhary@ kau.edu.sa (A. Bokhary), r_jassim@sesp.edu.sa (R. Jassim)

\section{To cite this article:}

Majed Alhazmy, Badr Habeebullah, Ahmad Bokhary, Rahim Jassim. Exergy Analysis of Combined Effect of Evaporative Cooling and Steam Injection on Gas Turbines Performance Enhancement in Hot and Humid Climates. American Journal of Engineering and Technology Management. Vol. 2, No. 4, 2017, pp. 45-55. doi: 10.11648/j.ajetm.20170204.12

Received: August 13, 2017; Accepted: August 28, 2017; Published: October 25, 2017

\begin{abstract}
In this paper, an exergy analysis has been used to examine for a combination of cooling the compressor intake air and inject steam in the combustion chamber the performance enhancement of gas turbine power plants using by a combination of intake air cooling the compressor intake air and injecting steam in the combustion chamber is studied. The limits of the cooling capability of an evaporative cooler are analyzed and formulated in terms of the characteristic dimensionless groups: the temperature ratio $\left(\xi_{\mathrm{T}}\right)$, the power gain ratio (PGR), Thermal efficiency change (TEC) and humidity ratio (RH). Similarly the effect of steam injected is presented as a ratio (y) of total volumetric flow rate. The effect of different pressure ratio (PR) is examined for Saudi Arabia summer weather when the turbine inlet temperature, $\mathrm{T}_{3}$, is a predetermined of $1373.15 \mathrm{~K}$. The results for a specific example where the air evaporative cooler drops the temperature to the wet bulb temperature is presented and show the power gain ratio enhancement depends on the ambient temperature, relative humidity, evaporative cooler effectiveness and slightly on the pressure ratio. The results indicate for PR $=10$, the PGR is enhanced by $9 \%$ at $20 \%$ relative humidity and drops to $3.37 \%$ at $60 \%$ relative humidity. The daily performance of the cooling method is examined for the hot humid conditions of Jeddah, Saudi Arabia. The results show that the evaporative cooler increased both the daily power output and the thermal efficiency by $2.52 \%$ and $0.112 \%$ respectively. In addition, the result shows that the combustion irreversibility is the dominant in the governing the system PGR and TEC with various steam injection ratios for $P R=10$.
\end{abstract}

Keywords: Exergy Analysis, Gas Turbine, Air-Cooling, Steam Injection, Power Enhancement, Evaporative Cooler

\section{Introduction}

The electric power generation sectors in many countries face two real problems, the continuous increase in fuel prices and the incessant growth in energy demand. Utilities focus considerable attention on methods and techniques to improve the performance of their generation units. There are many attempts to improve the performance of thermal systems. Among these, cooling the intake air and the steam-injected gas turbine system which both have approved technologies and commercialized and have played important roles in the electricity generation industries because their performance greatly improved the output power of GT power plant. In hot climate countries, as summer temperature rises, GT performance decreases. At the same time and because of the reliance on space air conditioning, the demand for power increases. Cooling the air at the compressor intake increases the air density and help boosting the power output. In addition, the ambient air humidity ratio plays an important role on selection of the cooling process. Several air intake cooling techniques are in use such as evaporative cooling, mechanical, absorption chillers and ice thermal storage. Each of these methods has its advantages and limits. Also, most recently, steam has been injected around the fuel nozzle tips for controlling NOx production. In this paper the limits of air-cooling by direct evaporative cooler combined with steam 
injection in the combustion chamber are investigated.

The components of a simple GT cycle are the compressor, combustion chamber and the turbine-generator set. The air temperature and humidity ratio at the inlet of the compressor affect the net efficiency and the plant heat rate. Several techniques are being used for inlet air-cooling, they can be broadly classified into direct and indirect methods. As mentioned earlier that the paper focus on the direct evaporative cooler only that combined with steam injection.

Several investigations are available that confirm the advantages of air cooling, the most recent of Alhazmy and Najjar [1] examined the power output and net efficiency of GT when using direct water spray process and surface cooling coils at the inlet of the compressor. For spray coolers the drop in air temperature by $3-15^{\circ} \mathrm{C}$ increased the power by $1-7 \%$. In case of water scarcity, they suggested the use of the condensate from the waste gases to recover partially for the spray water. There are different methods in use for inlet aircooling, all with different limits but essentially constrained rates of success. Cortes and Willems [2] presented an overview on the current inlet air cooling technology, extensive review on the air cooling technology and its economic impact on the energy market was given by Darmadhkari and Andrepont [3].

Similarly, several works have been evaluated the GT performance characteristics with steam injection using traditional first law cycle analysis, based upon component performance characteristics coupled with energy balances, can invariably lead to the final correct result. Exergy analysis have been adopted by (Huang, et al.; [4]) reported that exergy destruction is significant in the combustion chamber. While, Jassim et.al [5] indicated that the major contribution comes from the combustion chamber where the irreversibility is the highest and presents 62 to $85 \%$ of the total irreversibility.

In the present study, an evaporative air cooler combined with steam injection was considered and analyzed. The objective is to boost the power output and enhance the thermal efficiency of gas turbines operating for long periods in a hot and humid climate. The performance of the cooling system is then presented in a dimensionless graph where the power gain and thermal efficiency enhancement can be evaluated easily for different ambient conditions.

\section{Description of Analysis}

In this study, a simple open type gas turbine cycle complied with steam injection system as shown in Figure 1 is considered. The cycle performances with cooling the compressor intake air by a direct evaporative air-cooling system to prevent tripping at high ambient temperature and injection of steam into the combustion chamber are evaluated. In addition, exergy analysis is used to evaluate the cycle components irreversibilities that is the dominant in governing the system cycle efficiency. The cooling is achieved by evaporation of water spray in an evaporative cooler installed ahead of the compressor inlet manifolds as seen in Figure 1. The ambient air enters the cooler at state o and enters the compressor at state 1 .

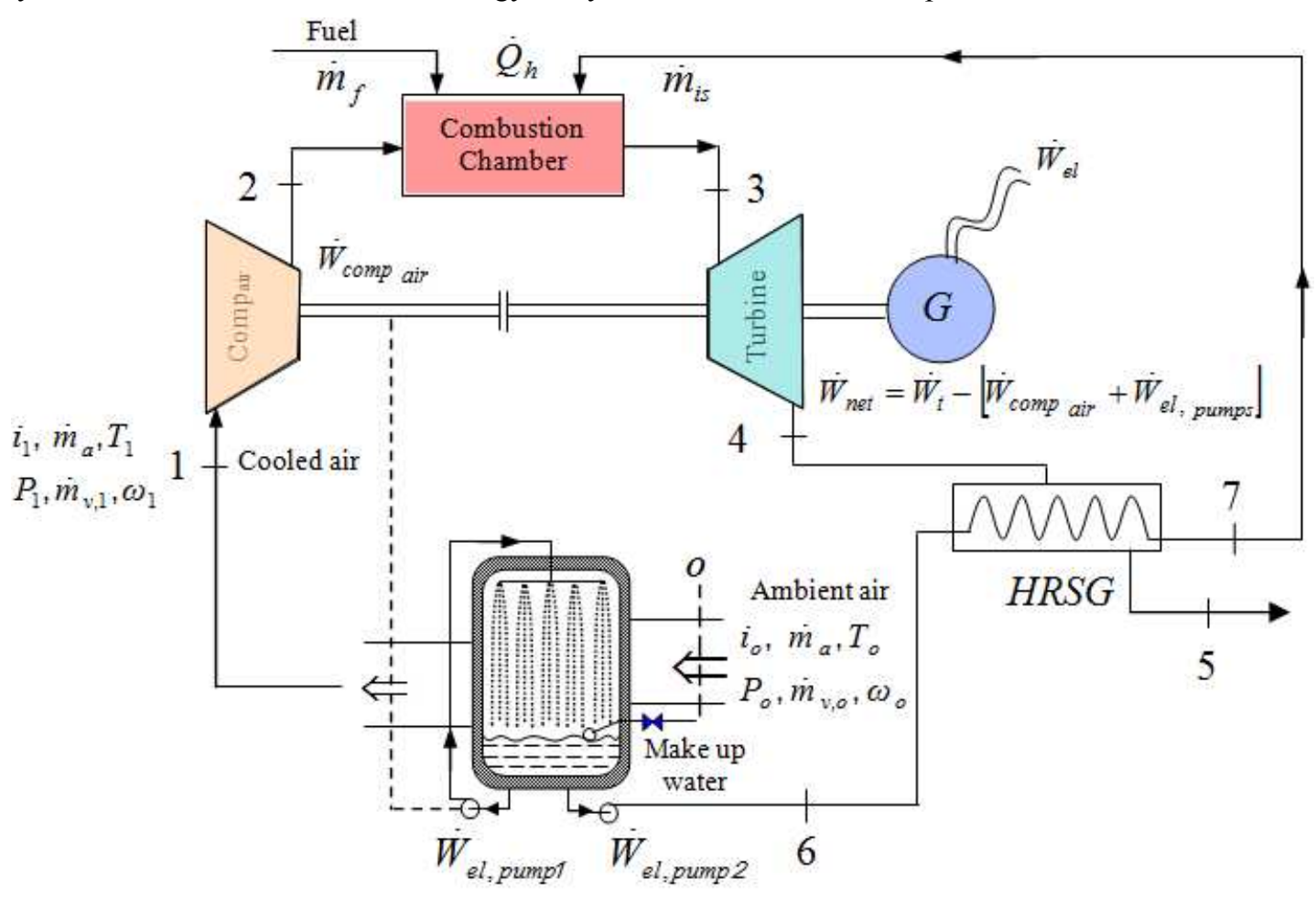

Figure 1. A simple open type gas turbine with a direct evaporative cooler and steam injection.

\subsection{Gas Turbine Cycle Analysis}

Consider an irreversible gas turbine cycle as shown in
Figure 2, processes 1-2 and 3-4 are irreversible and processes 2-3 and 4-1 are isobaric heat addition and rejection 
respectively. Processes $1-2 \mathrm{~s}$ and $3-4 \mathrm{~s}$ are isentropic presenting the process in an ideal cycle.

For the isentropic processes $1-2 \mathrm{~s}$ and $3-4 \mathrm{~s}$, we have

$$
\frac{T_{2 s}}{T_{1}}=\frac{T_{3}}{T_{4 s}}=\left[\frac{P_{2}}{P_{1}}\right]^{\frac{k-1}{k}}=P R^{\frac{k-1}{k}}
$$

where $\mathrm{PR}$ is the pressure ratio and $\mathrm{k}$ is the specific heats ratio.

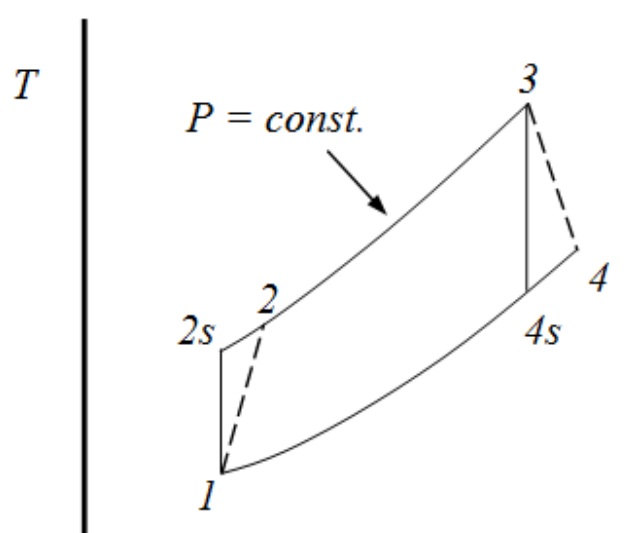

\section{$S$}

Figure 2. T-s diagram of an open type gas turbine cycle.

$$
\dot{E}_{\text {in }}+\dot{E}^{Q}=\dot{E}_{\text {out }}+\dot{W}+\dot{I}
$$

\subsubsection{Turbine}

If a cooling system (refrigeration machine) extracts its power from the turbine output as shown in Figure 1, the thermal efficiency of the cycle is

$$
\eta_{c y}=\frac{\dot{W}_{n e t}}{\dot{Q}_{h}}=\frac{\dot{W}_{t}-\left(\dot{W}_{\text {comp }_{\text {air }}}+\dot{W}_{\text {el,pumps }}\right)}{\dot{Q}_{h}}
$$

where $\dot{W}_{\text {el,pumps }}$ is the pumping power to circulate the water inside the evaporative cooler and through the heat recovery steam generator (HRSG).

Applying the first law of thermodynamics to the gas turbine (neglect the potential and kinetic energy terms), the power produced by the turbine is

$$
\dot{W}_{t}=\dot{m}_{t} c_{p g}\left(T_{3}-T_{4}\right)
$$

where $\dot{m}_{t}$ is the total gases mass flow rate at the turbine inlet given as

$$
\dot{m}_{t}=\dot{m}_{a}+\dot{m}_{v}+\dot{m}_{f}+\dot{m}_{s i}=\dot{m}_{a}\left(1+\omega_{1}+f+y\right)
$$

and $\omega_{1}$ is the humidity ratio at state 1 , Figure $1, f=\dot{m}_{f} / \dot{m}_{a}$ is the fuel air ratio, and $y=\dot{m}_{i s} / \dot{m}_{a}$ is the steam injection ratio.

The turbine isentropic efficiency is expressed as follows,

$$
\eta_{t}=\frac{T_{3}-T_{4}}{T_{3}-T_{4 s}} \Rightarrow T_{4}=T_{3}-\eta_{t}\left(T_{3}-T_{4 s}\right)
$$

From equations (1) and (4b)

$$
T_{4}=T_{3}-\eta_{t} T_{3}\left(1-\frac{1}{P R^{\frac{k-1}{k}}}\right)=T_{3}\left(1-\eta_{t}\left(1-\frac{1}{P R^{\frac{k-1}{k}}}\right)\right)
$$

Combined equations $4 \mathrm{a}$ and $4 \mathrm{c}$, we get

$$
\dot{W}_{t}=\dot{m}_{a}\left(1+\omega_{1}+f+y\right) c_{p g} \eta_{t} T_{3}\left(1-\frac{1}{P R^{\frac{k-1}{k}}}\right)
$$

The turbine isentropic efficiency can be estimated using the practical relations recommended by Korakianitis and Wilson [6] as:

$$
\eta_{t}=1-\left(0.03+\frac{P R-1}{180}\right)
$$
[1])

The gas specific heat is evaluated as (Alhazmy and Najjar,

$$
\begin{aligned}
c_{p g}= & 1.0887572 \times 10^{3}-1.4158834 \times 10^{-1} T+1.9160159 \times 10^{-3} T^{2} \\
& -1.2400934 \times 10^{-6} T^{3}+3.0669459 \times 10^{-10} T^{4}-2.6117109 \times 10^{-14} T^{5}
\end{aligned}
$$

The gas turbine is almost constant volume machine at a specific rotating speed, and then the inlet air volumetric flow rate, $\dot{V}_{a}$ is fixed regardless of the ambient air conditions. As the air temperature rises in hot summer days, its density falls but the volumetric flow rate remains constant. Therefore, the mass flow rate reduces and consequently the power output decreases (Ameri, et al., [7]). Equation 5 can be written in terms of the volumetric flow rate at the compressor inlet state as:

$$
\dot{W}_{t}=\dot{V}_{a} \rho_{a}\left(1+\omega_{1}+f+y\right) c_{p g} \eta_{t} T_{3}\left(1-\frac{1}{P R^{\frac{k-1}{k}}}\right)
$$

where $\rho_{a}$ is the moist air density which is a function of the temperature $\mathrm{T}_{1}$ and the humidity ratio $\omega_{1}$ and can be calculated using the Engineering Equation Solver (EES) software (Klein and Alvarado, [8]). The effect of the air pressure drop across chilling coils is small and can be neglected, hence $P_{1} \cong P_{0}$. The air density will vary significantly with humidity ratio change $\omega_{o} \rightarrow \omega_{1}$ and decrease in the air temperature $T_{o} \rightarrow T_{1}$.

The adiabatic gas turbine exergy balance is,

$$
\dot{I}_{t}=\dot{E}_{3}-\dot{E}_{4}-\dot{W}_{t}=\dot{V}_{a} \rho_{a}\left(1+\omega_{1}+f+y\right) T_{o}\left(s_{4}-s_{3}\right)
$$

\subsubsection{Air Compressor}

For humid air, the compression power can be estimated 
from:

$$
\dot{W}_{\text {comp }_{\text {air }}}=\dot{m}_{a} c_{p a}\left(T_{2}-T_{1}\right)+\dot{m}_{v}\left(i_{g 2}-i_{g 1}\right)
$$

where $i_{g 2}$ and $i_{g 1}$ are the enthalpies of saturated water vapor at the compressor exit and inlet states respectively, $\dot{m}_{v}$ is the mass of water vapor $=\dot{m}_{a} \omega_{1}$

Relating the compressor isentropic efficiency to the changes in temperature of the dry air and assuming that the compression of water vapor behaves as an ideal gas then

$$
\eta_{c}=\frac{T_{2 s}-T_{1}}{T_{2}-T_{1}}
$$

from which $T_{2}$ is expressed in terms of $T_{1}$ and the pressure ratio $\mathrm{PR}$ as

$$
\begin{gathered}
T_{2}=T_{1}\left[\frac{P R^{\frac{k-1}{k}}-1}{\eta_{c}}+1\right] \quad \begin{array}{c}
\text { 2.1.3. Combustion Chamber } \\
\text { Heat balance on the combustio } \\
\text { gives the heat rate supplied to the }
\end{array} \\
\dot{Q}_{h}=\dot{m}_{f} N C V=\dot{m}_{a} c_{p a}\left(T_{3}-T_{2}\right)+\dot{m}_{f} c_{p g} T_{3}+\dot{m}_{v}\left(i_{v 3}-i_{v 2}\right)+\dot{m}_{i s}\left(i_{3}-i_{7}\right)
\end{gathered}
$$

Introducing the fuel air ratio $f=\dot{m}_{f} / \dot{m}_{a}$ and substituting for $\mathrm{T}_{2}$ in terms of $\mathrm{T}_{1}$ from Eq. $10 \mathrm{~b}$ gives the cycle heat rate as:

$$
\dot{Q}_{h}=\dot{m}_{a} T_{1}\left[c_{p a}\left(\frac{T_{3}}{T_{1}}-\frac{P R^{\frac{k-1}{k}}-1}{\eta_{c}}-1\right)+f c_{p g} \frac{T_{3}}{T_{1}}+\frac{\omega_{1}}{T_{1}}\left(i_{v 3}-i_{v 2}\right)+\frac{y}{T_{1}}\left(i_{3}-i_{7}\right)\right]
$$

where f, as expressed in Alhazmy and Najjar [1] and modified to include the injected steam effect is:

$$
f=\frac{c_{p g}\left(T_{3}-298\right)-c_{p a}\left(T_{2}-298\right)+\omega_{1}\left(i_{v 3}-i_{v 2}\right)+y\left(i_{3}-i_{7}\right)}{N C V-c_{p g}\left(T_{3}-298\right)}
$$

$i_{\mathrm{v} 2}$ and $i_{\mathrm{v} 3}$ and are the enthalpies of water vapor at the combustion chamber inlet and exit states respectively and can be calculated from (Dossat, [9]):

$$
\mathrm{i}_{\mathrm{v}, \mathrm{j}}=2501.3+1.8723 \mathrm{~T}_{\mathrm{j}} \mathrm{j}=2 \text { or } 3
$$

The enthalpies of injected steam at point 3 and 7 can be evaluated at corresponding pressures and temperatures. Huang, et al. [4] specifies the exit temperature of injected steam in the heat exchanger of (HRSG) as

$$
T_{7}=T_{4}-56=T_{3}\left(1-\eta_{t}\left(1-\frac{1}{P R^{\frac{k-1}{k}}}\right)\right)-56
$$

Equation 16 is computed at the results have been presented in Figure 3.

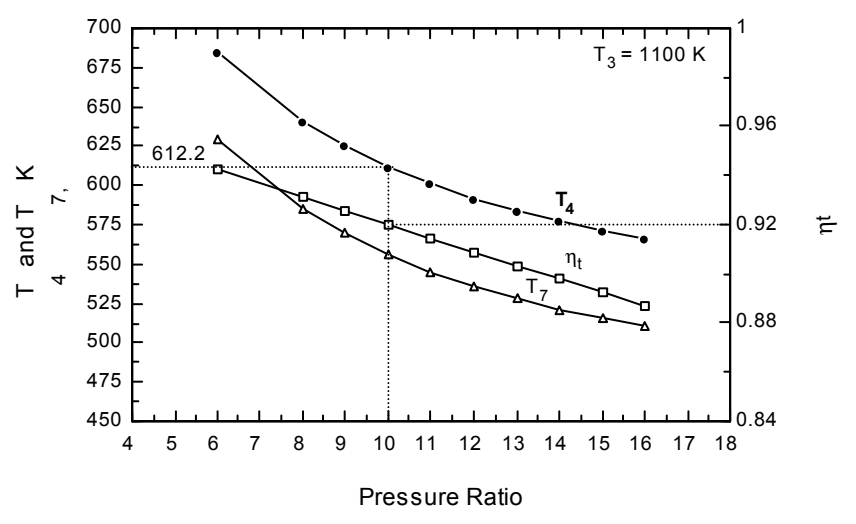

Figure 3. $T_{4}$ and $T_{7}$ variation with $P R$.

The combustion chamber irreversibility is

$$
\dot{I}_{c c}=\dot{E}_{f u e l}+\dot{E}_{2}+\dot{E}_{7}-\dot{E}_{3}
$$

Combustion process is often accomplished by heat transfer as well as fluid friction and mixing so there is usually more than one form of irreversibility present. In principle it is impossible to evaluate in this case what part of the combustion total irreversibility is due to any particular cause. The process of combustion can be examined, however by assuming that it takes place under adiabatic conditions and 
that irreversibilities due to friction and mixing are negligible.

The combustion chamber irreversibilities cab be expressed

$$
\dot{I}_{c c}=\dot{m}_{a} T_{o}\left\{\left(1+f+\omega_{1}\right)\left[c_{p g} \ln \left(\frac{T_{3}}{T_{o}}\right)-R_{g} \ln \left(\frac{P_{3}}{P_{o}}\right)\right]-\left(1+\omega_{1}\right)\left[c_{p a} \ln \left(\frac{T_{2}}{T_{o}}\right)-R_{a} \ln \left(\frac{P_{2}}{P_{o}}\right)\right]\right\}+T_{o} \Delta S_{o}
$$

where $T_{o} \Delta S_{o}$ is given

$T_{o} \Delta S_{o}=$ rate of exergy loss in combustion or reaction and expressed as

$$
=-\dot{\mathrm{m}}_{\mathrm{f}} \times \mathrm{NCV}+\varphi\left(\dot{\mathrm{m}}_{\mathrm{f}} \times \mathrm{NCV}\right)=\dot{\mathrm{m}}_{\mathrm{f}} \times \mathrm{NCV}(\varphi-1)=\dot{m}_{a} \times f \times N C V(\varphi-1)
$$

and

$$
R_{g}=\frac{c_{p g}(\gamma-1)}{\gamma}
$$

\subsubsection{Heat Recovery Steam Generator (HRSG)}

The HRSG consists of an economizer, an evaporator with drum and a superheater (Almutairi et.al, [10]). The output of the GT is passed through the a heat exchanger to recover the waste heat and to generate superheated steam and high pressure that is injected into the combustion chamber to be

$$
\dot{I}_{H R S G}=\dot{E}_{4}-\dot{E}_{5}-\left(\dot{E}_{7}-\dot{E}_{6}\right)+\dot{E}^{Q}=T_{o} \dot{m}_{a}\left[\left(1+\omega_{1}+f+y\right)\left(s_{4}-s_{5}\right)-y\left(s_{7}-s_{6}\right)\right]+\dot{Q}_{o}
$$

It is seen that the three terms of the gas turbine efficiency in Eq. $2\left(\dot{W}_{t}, \dot{W}_{\text {comp air }}\right.$ and $\left.\dot{Q}_{h}\right)$ depend on the air temperature and relative humidity at the compressor inlet whose values are affected by the type and performance of the cooling system.

\subsection{Direct Evaporative Water Spray Process}

In evaporative cooling water and intake air are brought into direct contact where the warm air stream transfers heat to sprayed water as seen in Figure 4a. During the air-water heat exchange process, part of the liquid water evaporates causing the temperature of the air to decrease adiabatically, line $0-1$ in Figure $4 \mathrm{~b}$. The air humidity ratio increases from $\omega_{o}$ to $\omega_{1}$ approaching the saturation condition. As the air approaches the saturation limit, the evaporation process takes more time where the air cannot carry more water and further water injection is not utilized. Therefore, the direct evaporative cooling of air is limited by the temperature difference $\left(T_{0}-T_{1}\right)$. In practice to cool the air to the saturation state, requires water over spraying that may initiate carry over of droplets causing fouling of compressor blades and/or rust of the entrance ducts. Controlling the parameters of evaporative coolers is an important key to the successful seasonal operation of coolers. The effectiveness of an evaporative air-cooler $\left(\varepsilon_{e v c}\right)$ is defined as the ratio between the actual dry bulb temperature decrease to the theoretical temperature difference if the air leaves the cooler at saturation state. Typical evaporative cooler effectiveness range is 0.8 to 0.9 (Cortes and Willems, [2]).

Figure $4 \mathrm{a}$ shows a schematic of a evaporative cooler where the ambient air at $\mathrm{T}_{\mathrm{o}}, \omega_{o}$ and $\mathrm{P}_{\mathrm{o}}$ enters the spray chamber and mixed with the fuel or is injected around the fuel nozzle tips for controlling $\mathrm{NO}_{\mathrm{x}}$ production. the energy balance is:

$$
\dot{m}_{7}\left(i_{7}-i_{6}\right)=\dot{m}_{t} c_{p g}\left(T_{4}-T_{5}\right)
$$

The total mass flow rate $\dot{m}_{t}$ and $\mathrm{T}_{4}$ are evaluated from equations $4 \mathrm{a}$ and $4 \mathrm{c}$ respectively. While $\mathrm{T}_{5}$ is limited in this study to sulphur erosion limit which is $130^{\circ} \mathrm{C}(403.15 \mathrm{~K})$ (Huang, et al.; 2000).

The HRSG irreversibility is

leaves at $T_{1}, \omega_{1}$ and $P_{1}$. The evaporative cooler is assumed to operate in a steady adiabatic process such that the ambient moist air enters at $\mathrm{T}_{\mathrm{o}}$ and $\mathrm{RH}_{\mathrm{o}}$ and leaves at state 1. Adequate quantity of water is added to the air stream to raise its moisture content close to that corresponding to $100 \%$ relative humidity and decrease its temperature as seen in Figure $4 \mathrm{~b}$. Applying energy balance yields (Mc Quiston, et al., [11])

$$
\omega_{o}\left(i_{v o}-i_{w}\right)=c_{p a}\left(T_{1}-T_{o}\right)+\omega_{1}\left(i_{f g 1}\right)
$$

where $i_{v o}$ and $i_{w}$ are saturated water vapor enthalpy at $T_{o}$ and saturated water liquid enthalpy at $\mathrm{T}_{1} \cdot \mathrm{i}_{\mathrm{fg} 1}$ is the latent heat of vaporization at state $1 . \omega_{0}$ is evaluated at the ambient conditions using EES software.

The evaporative cooler irreversibility is

$$
\dot{I}_{e c}=\dot{E}_{o}-\dot{E}_{1}=T_{o} \dot{m}_{a}\left(s_{o}-s_{1}\right)
$$

\section{Gas Turbine Coupled to an Evaporative Cooler}

In order to evaluate the feasibility of a cooling system coupled to a GT plant, the performance of the plant is examined with and without the cooling system. In general the net power output of a complete system is:

$$
\dot{W}_{n e t}=\dot{W}_{t}-\left(\dot{W}_{\text {comp }_{\text {air }}}+\dot{W}_{\text {el,pump } 1+2}\right)
$$

The three terms of Eq. 24 are functions of the air properties at the compressor intake $\left(\mathrm{T}_{1}\right.$ and $\left.\omega_{1}\right)$, which in 
turn depends on the performance of the cooling system. Let us define a dimensionless term that gives the advantage of using any cooling system as the power gain ratio (PGR)

$$
P G R=\frac{\dot{W}_{\text {net,withcooling }}-\dot{W}_{\text {net, without cooling }}}{\dot{W}_{\text {net }, \text { without cooling }}} \times 100 \%
$$

The PGR is a generic term that takes into account all the parameters of the GT and the associated cooling system irrespective of the cooling process. For a stand-alone GT under specific climatic conditions $\mathrm{PGR}=0$. If a cooling system is used, the PGR increases with the reduction of the intake temperature but this increase is restricted by the physical limits of the cooling process. However, the PGR gives the percentage enhancement in power generation the thermal efficiency of a coupled system is an important parameter to describe the input output relation. Let us define another factor that physically relates the thermal efficiency of a stand-alone GT to that coupled to a cooling system as the thermal efficiency change (TEC)

$$
T E C=\frac{\eta_{c y, \text { withcooling }}-\eta_{c y, \text { without cooling }}}{\eta_{c y, \text { without cooling }}} \times 100 \%
$$

However, the PGR is always positive TEC can be negative, which means that the efficiency of the coupled system is less than that of a stand-alone GT even at low intake temperatures. Both PGR and TEC provide dimensionless parameters that can be easily employed and interpreted.

For evaporative cooling the power consumed by the cooling system, $\dot{W}_{\text {el,pump }}$ is the pumping power to circulate the water inside the chamber (see Figure 4a). This power is small compared to the other terms in equation 24 , and can be ignored. Therefore, the PGR for a gas turbine with evaporative cooler can be obtained from substituting equations 5, 11 and 24 into equation 25 . From equations 2, 5, 11 and 24 the cycle thermal efficiency with cooling, $\eta_{c y, e v c}$, in terms of the air properties at the compressor intake and the fuel air ratio can be expressed as,

$$
\eta_{c y, e c}=\left\{\left(1+\omega_{1}+f\right) c_{p g} \eta_{t} \frac{T_{3}}{T_{1}}\left(1-\frac{1}{P R^{\frac{k-1}{k}}}\right)-\left[c_{p a} \frac{1}{\eta_{c}}\left(P R^{\frac{k-1}{k}}-1\right)+\frac{\omega_{1}}{T_{1}}\left(i_{g 2}-i_{g 1}\right)\right]\right\} /\left[(1+f) c_{p g} \frac{T_{3}}{T_{1}}-c_{p a}\left(\frac{P R^{\frac{k-1}{k}}-1}{\eta_{c}}+1\right)+\frac{\omega_{1}}{T_{1}}\left(i_{v 3}-i_{v 2}\right)\right]
$$

Equation 27 for an ideal air reversible cycle, when $\eta_{c}=\eta_{t}=1$, fuel air ratio $\mathrm{f}=0, c_{p g}=c_{p a}$ and the inlet air humidity ratio $\omega_{1}=0$, gives the standard expression in which the pressure ratio is the only dependent

$$
\left(\eta_{c y, r e v}=1-1 / P R^{(k-1) / k}\right) \text {. }
$$

For a stand-alone (without cooling) GT the third term of the nominator vanishes and the inlet conditions $T_{1}$ and $\omega_{1}$ are replaced by $T_{0}$ and $\omega_{o}$.

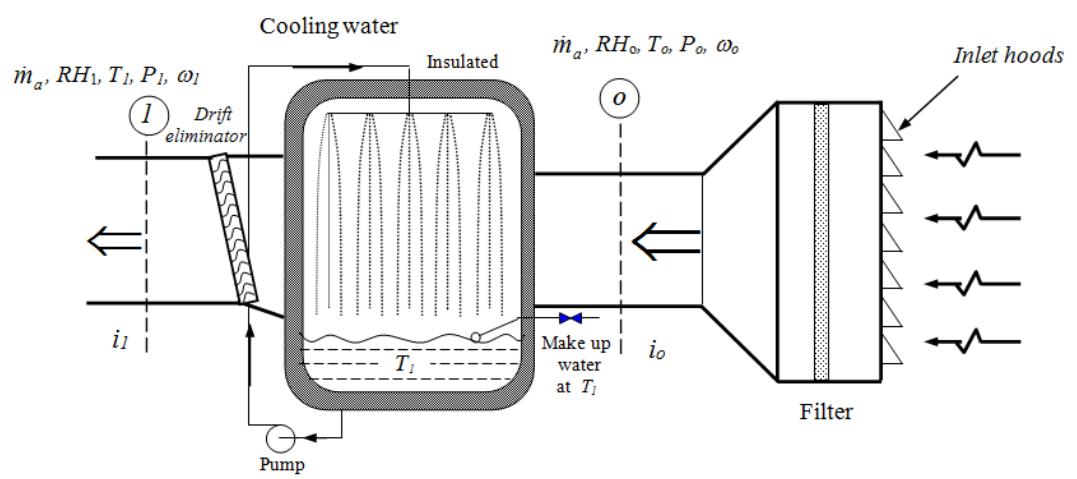

Figure 4a. Schematic of adiabatic evaporative cooler.

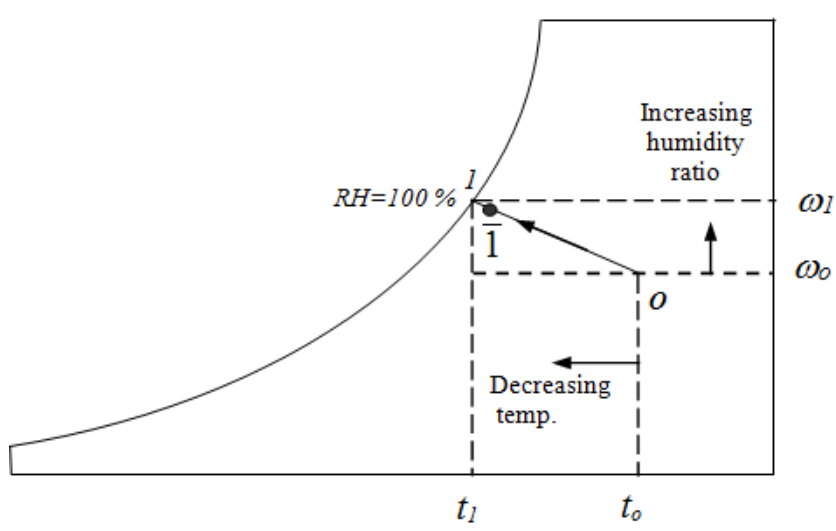

Figure 4b. Adiabatic saturation process on the psychrometric chart. 


\section{Results and Discussion}

In order to investigate the performance of the direct evaporative cooling method on the GT power output and thermal efficiency, a computer program has been developed to calculate the PGR and TEC for different operation conditions. The thermophysical properties were determined to the accuracy of the EES software (Klein and Alvarado, 2004). In particular, the specific heats of air and combustion gases which are both temperature dependent. Table 1 shows the range of the different operating parameters for the present analysis.

Table 1. Range of parameters for the present analysis.

\begin{tabular}{ll}
\hline Parameter & Range \\
\hline Ambient air & \\
Max. ambient air temperature, $\mathrm{T}_{\mathrm{o}, \max }$ & $323.15 \mathrm{~K}$ \\
Relative humidity, $\mathrm{RH}_{\mathrm{o}}$ & $0 \% \rightarrow 100 \%$ \\
Volumetric air flow rate & $1 \mathrm{~m}^{3} / \mathrm{s}$ \\
Gas Turbine & 10 \\
Pressure ratio $\mathrm{P}_{2} / \mathrm{P}_{1}$ & $1373.15 \mathrm{~K}$ \\
Turbine inlet temperature $\mathrm{T}_{3}$ & $0.91 \rightarrow 0.93$ \\
Turbine efficiency $\eta_{t}$, Eq.6 & $0.88 \rightarrow 0.91$ \\
Air compressor efficiency $\eta_{c}$, Eq. 12 & \\
\hline
\end{tabular}

The selected maximum air temperature $t_{\mathrm{o} \text {, max }}$ is based on meteorological data recorded during the past few years in Saudi Arabia, which was close to $50^{\circ} \mathrm{C}$. An average design value of $44.5 \%$ for the relative humidity is selected as base data. Even though, the performance of cooling system under actual weather conditions is also considered.

For fixed values of $T_{3}, T_{0}$, and $\mathrm{RH}_{0}$ assuming that the maximum cooling can be achieved if the air is cooled to the wet bulb temperature and the pumping power $\dot{W}_{e l, p u m p}$ is neglected. Figure 5 shows the network is a function of PR. As can be seen, the net gas turbine power output increases with pressure ratio until it reach a maximum at $P R=10$ after which the power declines. The same trend is observed for the gas turbine when coupled to a cooling system. Increasing the pressure ratio causes increase in both the turbine and compressor powers but at different rates. The maximum power occurs at a PR where the rate of increase in the turbine power is greater than that required to drive the air compressor. For larger values of PR, the network tends to decrease as a result of the percentage increase in power required to drive the air compressor as shown in Figure 6. Figure 6 shows also that the maximum net output power falls approximately between pressure ratio of $8 \rightarrow 12$.

Figure 7 shows the thermal efficiency variation with pressure ratio for different turbine inlet absolute temperature. As the maximum temperature $T_{3}$ is kept constant (1373.15 $\mathrm{K})$, an increase in pressure ratio will increase the cycle efficiency. However, there is a limit to the pressure ratio. The ratio will reach the maximum limit when the air temperature at the compressor outlet is equal to the design turbine inlet temperature. In this case, the cycle net work tends towards zero, and the cycle efficiency approaches the reversible efficiency (Kam and Priddy, [12]). In the present case study where the direct evaporative cooler is used to cool the outlet air temperature from $50^{\circ} \mathrm{C}$ to wet bulb temperature $\left(37.12^{\circ} \mathrm{C}\right)$ increases the term $\mathrm{T}_{3} / \mathrm{T}_{1}$ from 4.25 to 4.425 . Consequently, the thermal efficiency increases as seen by the trends in Figure 7. Figure 8 shows the thermal efficiency of the gas turbine is improved by $0.24 \%$ for evaporative cooling and it is of positive magnitude.

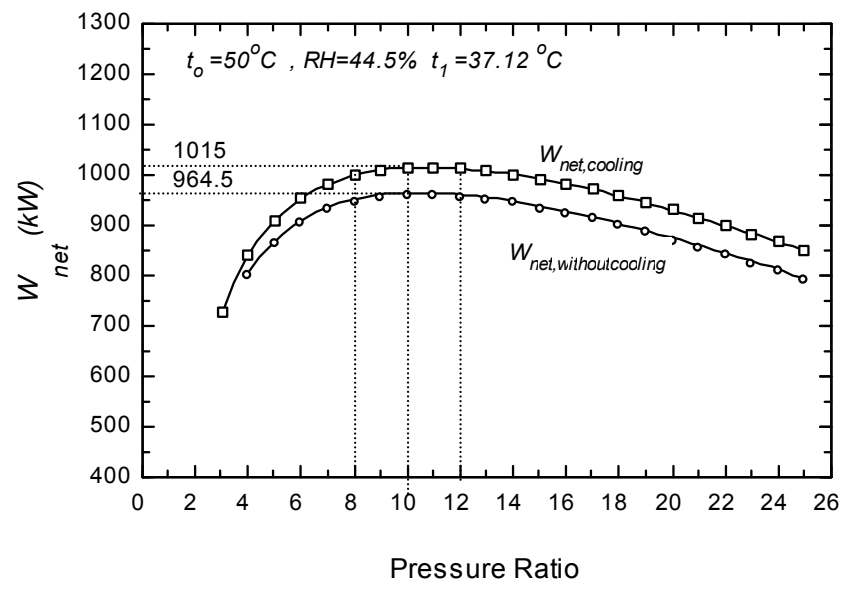

Figure 5. Dependence of network on the pressure ratio.

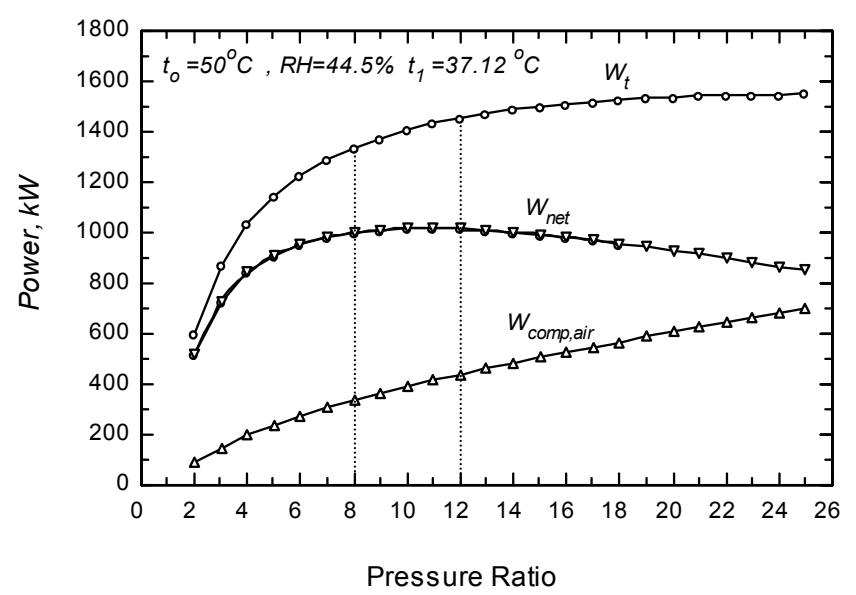

Figure 6. The power for a gas turbine system using a direct evaporative cooler.

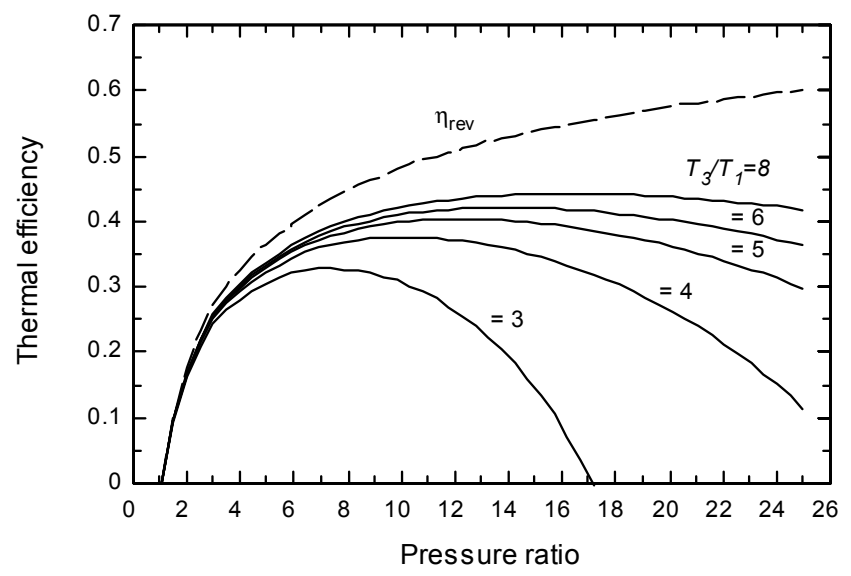

Figure 7. The thermal efficiency of a simple gas turbine cycle. 


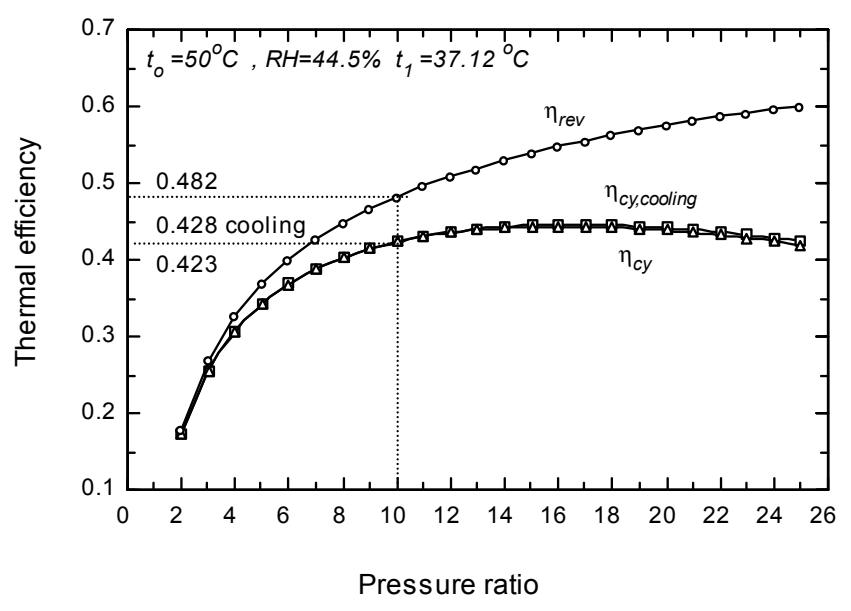

Figure 8. Dependence of thermal efficiency on pressure ratio of a direct evaporative cooler.

Applying equations 25 and 26 for an evaporative air cooler system, the variation of the PGR and TEC with the temperature ratio $\xi_{T}=t_{1} / t_{o}$ is obtained and presented in Figure 9. The factor $\xi_{T}$ presents physically the ratio between the air temperatures at the cooler exit and the ambient temperature in Celsius (cooling process attainment). For a constant pressure ratio, the PGR increases with decreasing of $\xi_{T}$ and a power gain factor of $4 \%$ can be obtained by cooling the air from $50^{\circ} \mathrm{C}$ to $40^{\circ} \mathrm{C}$ for PR of 10 .

The evaporative air cooler is designed to lower the ambient air temperature to a degree close to the ambient wet bulb temperature that limits its cooling capability in humid climate areas. Applying equations 25, 26 and 27 with the assumption of that $\dot{W}_{\text {el,pump }}$ is zero, the PGR and TEC are computed for fixed ambient conditions as seen in Figure 9. For $50^{\circ} \mathrm{C}$ and $44.5 \%$ relative humidity, the air temperature can be theoretically reduced in an adiabatic process to $37.12^{\circ} \mathrm{C}$ (wet bulb temperature) for which $\xi_{T}=0.74$. From Figure 9 at $\xi_{T}=0.74$ and PR of 10, the power gain reaches $4.8 \%$ and the thermal efficiency change is $0.22 \%$. However, the value is small but substantiates an improvement in efficiency. This result shows that for evaporative cooling there is gain in power and improvement in thermal efficiency. This advantage is soon offset by the fact that the system cannot provide any further improvement beyond the limiting state at specified ambient conditions.

Figure 10 shows the PGR and TEC for different ambient air temperatures $\left(50^{\circ} \mathrm{C}, 40^{\circ} \mathrm{C}\right.$ and $\left.30^{\circ} \mathrm{C}\right)$ and the whole range of $\mathrm{RH}$ up to $100 \%$. The curves on the figure present the variation of the RH with $\xi_{T}$ at the maximum gain, which equals $t_{w b} / t_{o}$. Therefore, these curves determine the limiting condition for evaporative cooling once the ambient temperature and relative humidity are prescribed. For example to determine the maximum power gain ratio and thermal efficiency change for ambient conditions of $50^{\circ} \mathrm{C}$ and $60 \% \mathrm{RH}_{\mathrm{o}}$; first draw a horizontal line from $60 \%$ relative humidity until it intersects the cooling limit of $\mathrm{t}_{\mathrm{o}}=50^{\circ} \mathrm{C}$ point $\mathrm{A}$ on the figure. At this point $\xi_{T}$ determines the lowest air temperature at the compressor inlet, intersection with the lines of PGR and TEC (at $\mathrm{t}_{\mathrm{o}}=50^{\circ} \mathrm{C}$ ) gives the maximum values of the PGR and TEC as $3.37 \%$ and $0.157 \%$ respectively. Further, the results in Figure 10 are presented for an ideal evaporative cooler effectiveness $\varepsilon_{\text {evc }}=100 \%$, where (see Figure 4b)

$$
\varepsilon_{\text {evc }}=\frac{t_{o}-t_{\overline{1}}}{t_{o}-t_{1}}=\frac{1-\xi_{T, A}}{1-\xi_{T}}
$$

where $\xi_{T, A}$ is the ratio of the actual air temperature at the cooler exit to the ambient air temperature in Celsius and is equal to $t_{\overline{1}} / t_{o}$. Form equation $28 \xi_{T, A}$ can be expressed as,

$$
\xi_{T, A}=1-\varepsilon_{e v, c}\left(1-\xi_{T}\right)
$$

To include the effectiveness, $\varepsilon_{\text {evc }}$, in the analysis, just replace $\xi_{T}$ by $\xi_{T, A}$ and the PGF and TEC can be evaluated from Figure 10. The effect of evaporative cooler effectiveness on both the PGR and TEC is shown in Table 2 for $\varepsilon_{e v c}$ is equal to 0.85 .

The relative humidity of ambient air is a key parameter for the evaporative cooler cooling capability. For illustration, let us consider air at constant dry bulb temperature of $40^{\circ} \mathrm{C}$ and $60 \% \mathrm{RH}_{0}$, for which the maximum PGR and TEC are $3.013 \%$ and $0.137 \%$ respectively. For this case $\xi_{T}=0.814$, which means that the air temperature can only be reduced from 40 to $32.56^{\circ} \mathrm{C}$. For an intermediate level of humidity, $40 \%$, and the same dry bulb temperature the corresponding temperature ratio $\xi_{T}$ is 0.696 , for which the temperature limit is $27.83^{\circ} \mathrm{C}$. The corresponding power gain is $5.012 \%$. The detailed results for the effect of the $\mathrm{RH}$ on the evaporative cooling capacity are summarized in Table 2, which shows a direct inverse proportionality.

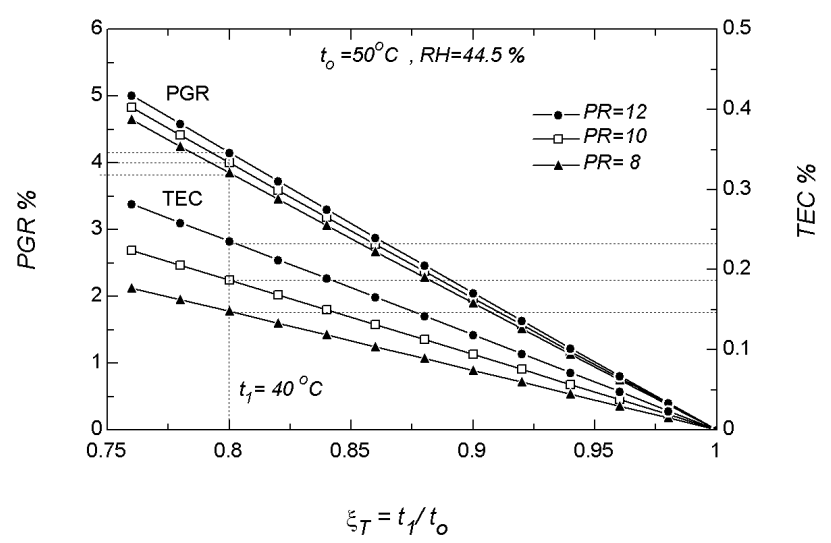

Figure 9. Variation of the power gain ratio, thermal efficiency change and the temperature ratio for a gas turbine with direct inlet air evaporative cooling. 
Table 2. The maximum PGR and TEC with different ambient air conditions and evaporative cooler effectiveness.

\begin{tabular}{|c|c|c|c|c|c|c|c|c|c|}
\hline \multicolumn{2}{|c|}{ Ambient air conditions } & \multicolumn{4}{|c|}{ Evaporative cooler with $\varepsilon_{e v c} 100 \%$} & \multicolumn{4}{|c|}{ Evaporative cooler with $\varepsilon_{e v c} 85 \%$} \\
\hline $\mathbf{t}_{\mathbf{0}}{ }^{\circ} \mathbf{C}$ & $\mathrm{RH}_{0} \%$ & $\mathbf{t}_{1}{ }^{\circ} \mathrm{C}$ & $\xi_{T}$ & PGR \% & TEC \% & $t_{\overline{1}}{ }^{\circ} \mathbf{C}$ & $\xi_{T A}$ & PGR \% & TEC \% \\
\hline 40 & 60 & 32.56 & 0.814 & 3.013 & +0.137 & 33.68 & 0.842 & 2.55 & +0.116 \\
\hline 40 & 40 & 27.83 & 0.696 & 5.012 & +0.223 & 29.66 & 0.742 & 4.234 & +0.190 \\
\hline 40 & 20 & 22.03 & 0.551 & 7.546 & +0.328 & 24.73 & 0.618 & 6.359 & +0.280 \\
\hline 40 & 10 & 18.57 & 0.464 & 9.102 & +0.39 & 21.79 & 0.545 & 7.658 & +0.333 \\
\hline
\end{tabular}

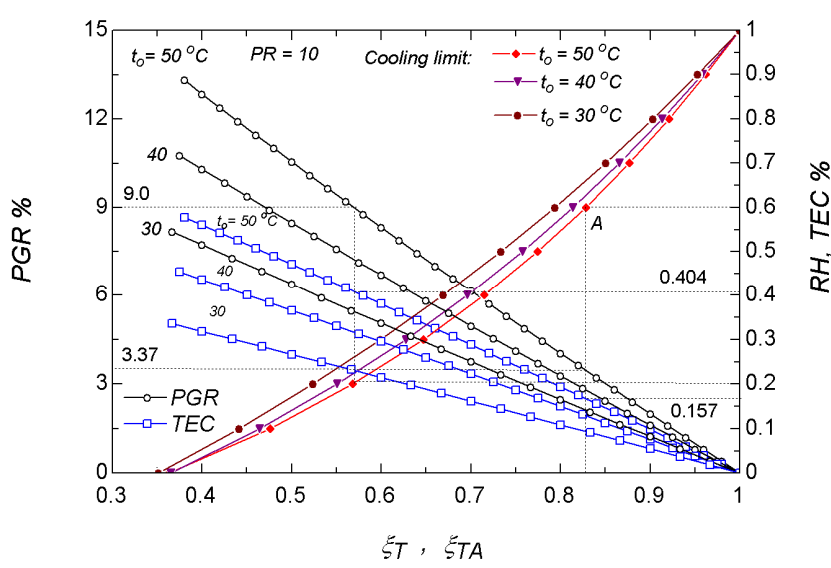

Figure 10. The cooling limit of air evaporative cooler.

In order to examine the daily performance of the cooling system let us assume system reduce the intake air temperature from $T_{0}$ to $T_{1}$, for which the evaporative cooler effectiveness is $100 \%$ and operate for 24 hours. Applying equations 25 and 26, on hourly basis, using the ambient data of Figure 11. The variation of the PGR and TEC for the evaporative cooler is presented in Figure 12. Figure 12 shows that during early morning hours with the $100 \%$ RH the power gain ratio PGR and thermal efficiency change TEC drop rapidly to reach zeros at 6 AM where $\xi_{T}$ approaches 1. At 11 AM with $40.1{ }^{\circ} \mathrm{C}$ air temperature and $\mathrm{RH}$ of $34.1 \%$, the gain reaches $5.706 \%$ and the thermal efficiency improvement is, $0.253 \%$, where the humidity is the least.

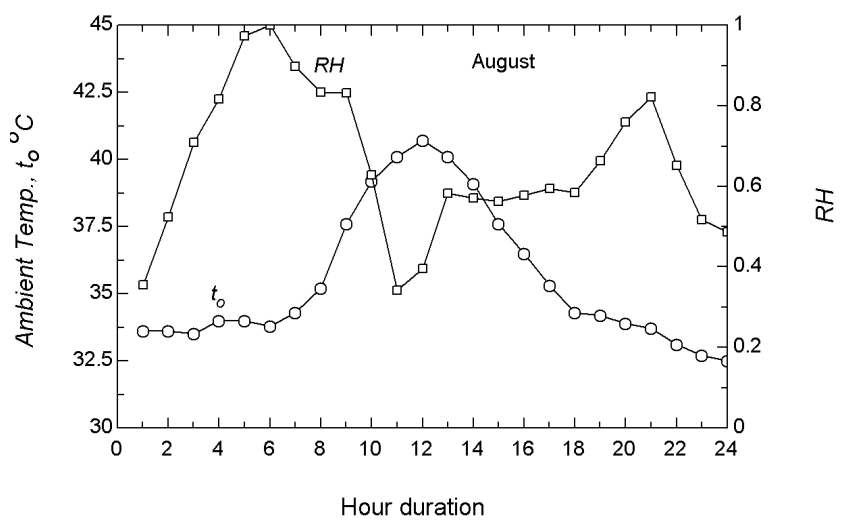

Figure 11. August RH and ambient temperature variations.

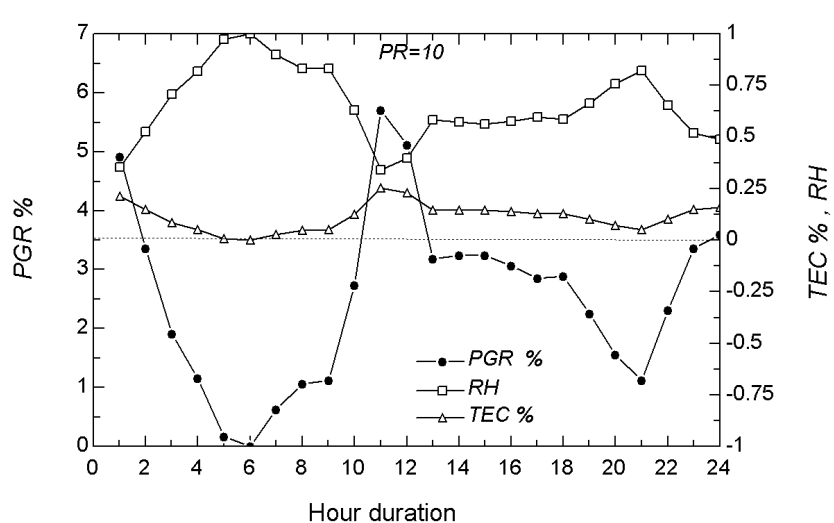

Figure 12. Dependence of gas turbine maximum PGR on RH of direct evaporative cooler.

The values show that the cooling system may be promising when operated under favorable conditions but the overall daily performance is what counts at the end. The practical illustrative application indicates that the evaporative system provides additional energy of $2.52 \%$.

In addition to its features in improving the combustion process and reducing the harmful environmental effects, injecting steam into the combustion chambers increases the mass of the working fluid expanding in the turbine and therefore the power output from the gas turbine unit. Figure 13 shows the variation of the net power output with the pressure ratio for three considered configurations. The reference configuration is that of a typical gas turbine unit (Brayton cycle), the second is a gas turbine unit fitted with air cooler at the gas turbine intake and the third is like the second configuration but with steam injection into the combustion chambers. The three configurations show follow the operation of a Brayton cycle, however, the third configuration (injecting steam into the combustion chamber which is held fixed at $10 \%(y=0.1)$ and cooling the air at the compressor intake) produces more net power output than the other two. The increment starts small at the low-pressure ratios then increase as the pressure ratio increases before it stabilizes at high-pressure ratios. With a pressure ratio of 4 , injecting steam increases the net power by $11 \%$ higher than the basic unit. Moreover, injecting steam and cooling air at the unit intake increases the output by $17.5 \%$. Similarly, operating at a pressure ratio of 10 or more shows that injecting steam helps increasing the net power output by $14 \%$, this increment becomes $20 \%$ when intake cooling and steam injection are both used. The increments in the net power are shown in 
Figure 14 as a net power gain ratio (PGR).

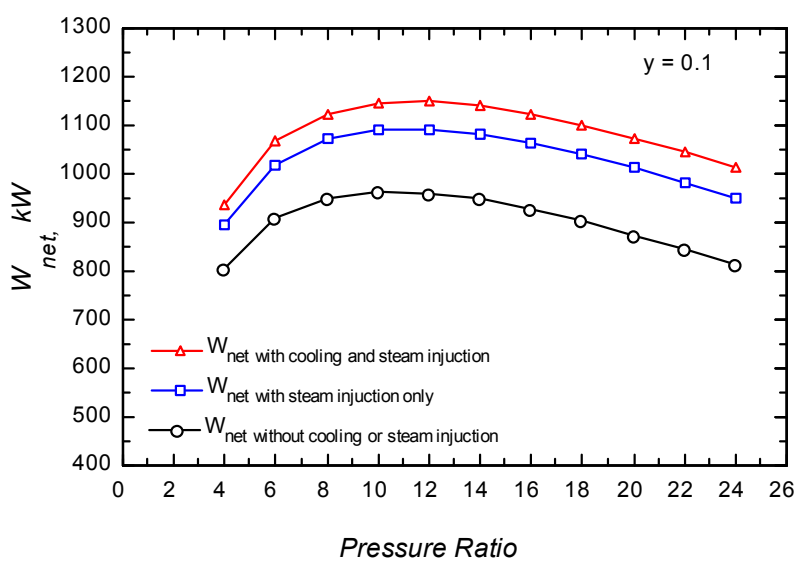

Figure 13. Dependence of gas turbine network on PR and the mass injection percentage.

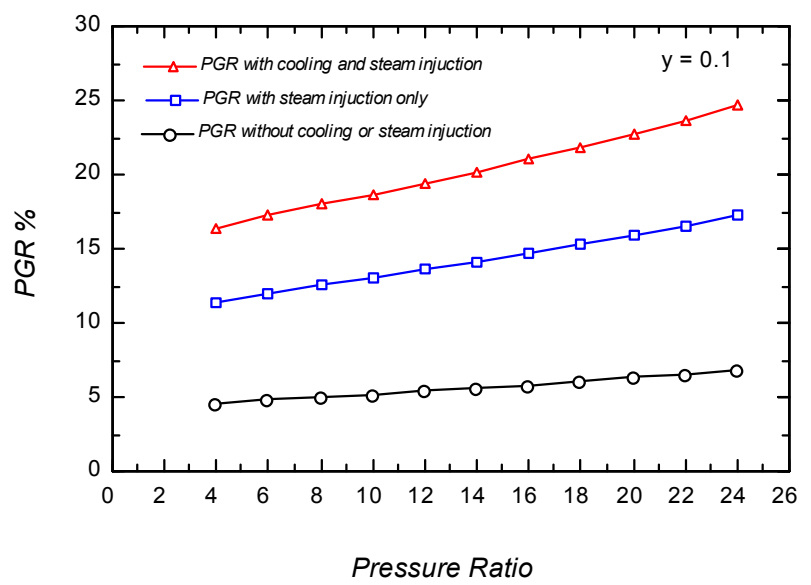

Figure 14. Variation of the power gain ratio with $P R$ at $10 \%$ of steam injection.

The input heat requirement is also affected by intake cooling and steam injection. The basic cycle where neither intake cooling is used nor steam injection has the least heat input requirement. This is expected since cooling reduces the temperature of air entering the compressor. Moreover, both cooling and steam injection increases the mass of the flow through the combustion chamber. Figure 15 shows variation of the heat consumption in each of the three configuration with the pressure ratio. The steam injection in third configuration is held fixed at $10 \%(\mathrm{y}=0.1)$ of the flow. It is obvious that increasing the pressure ratio reduces the heat consumption since high-pressure ratio compression increases the delivery temperature of the compressor. For a pressure ratio of 4 injection of steam only increases the heat consumption by $1.3 \%$ more than that of the reference unit. The increment becomes $6 \%$ when both cooling and steam injection are used. At higher pressure ratios the increments become $7.5 \%$ with steam injection only and $12 \%$ with steam injection and intake cooling.

The variations of the net power output and the heat consumption have its direct effect on the thermal efficiency change (TEC) of each configuration. Figure 16 shows the percentage change in the thermal efficiency with pressure ratio from the three configurations.

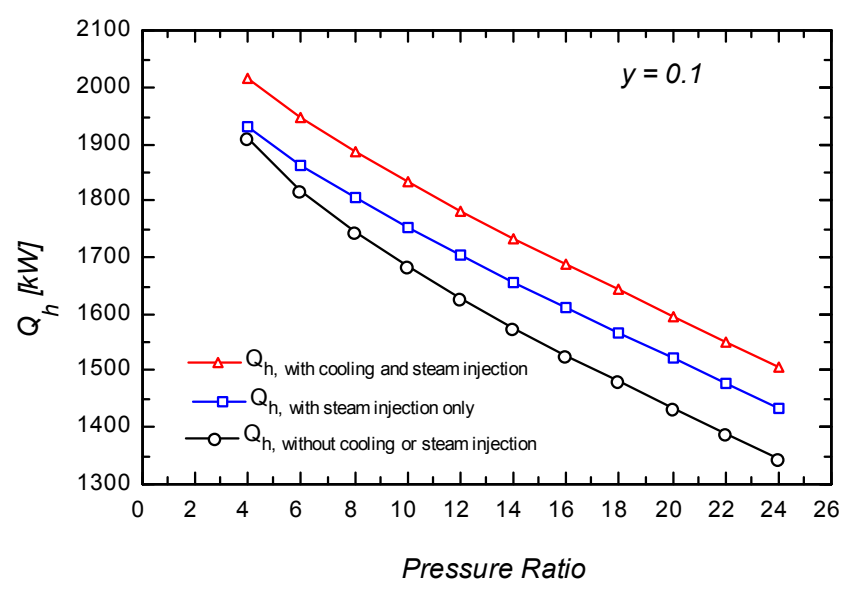

Figure 15. Dependence of gas turbine maximum $Q_{h}$ on $P R$.

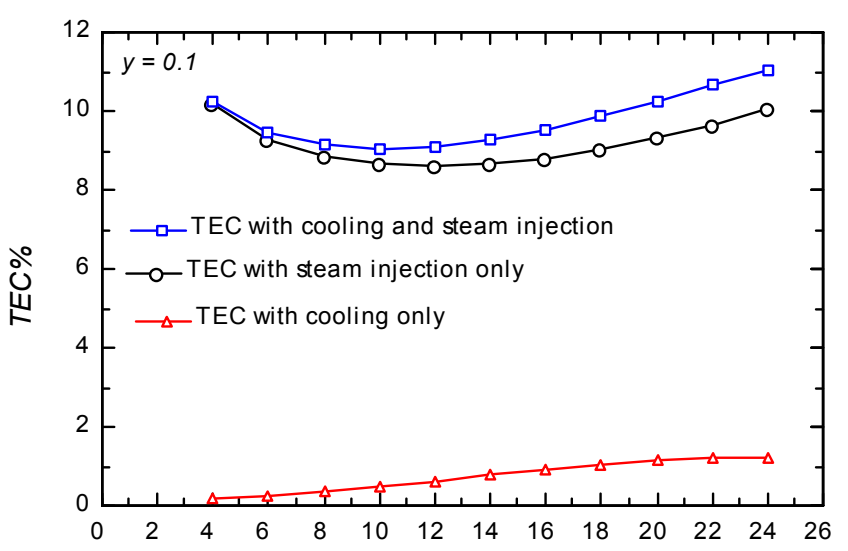

Pressure Ratio

Figure 16. Variation of the thermal efficiency change TEC and PR with different scenarios.

\section{Conclusions}

The effect of inlet air cooling on the performance of a simple gas turbine plant is investigated. Systematic analysis of a GT cycle coupled to a cooling system is presented for an evaporative air cooling process. The performance improvement showed strong dependency on the climatic conditions, evaporative cooler effectiveness and to some degree on the gas turbine pressure ratio. The evaporative cooling is quite efficient for dry air, for $40^{\circ} \mathrm{C}$ and $10 \% \mathrm{RH}$ ambient air, the maximum power gain and the thermal efficiency improvements are $9.102 \%$ and $0.39 \%$ respectively. The direct evaporative cooling process is limited by the wet bulb temperature at which additional water spray would not contribute any further cooling effects. The performance of the evaporative cooling is presented in a general dimensionless working graph that directly relates the maximum power gain and thermal efficiency variation to the ambient conditions. Finally, the performance of the air cooling system was examined for the hot and humid conditions of Jeddah Saudi Arabia. The actual climate on 
August 16 is selected as base data for investigation. The daily power output and the thermal efficiency improvement were only $2.52 \%$ and $0.112 \%$ respectively.

In addition to improving the thermal efficiency and power gaining, evaporative cooler improves the environmental impact of the GT, since increasing water vapour in the inlet air tends to lower the amount of nitrogen oxides emissions as well as reduces the dust due to air washing.

\section{Acknowledgements}

This project was funded by the National Plan for Science, Technology and Innovation (MAARIFAH)-King Abdulaziz City for Science and Technology-the kingdom of Saudi Arabia-award number (8-ENE 288-03). The authors also, acknowledge with thanks the Science and Technology Unit, King Abdulaziz University for technical support.

\section{Notations}

$\begin{array}{ll}\mathrm{c}_{\mathrm{p}} & \text { specific heat at constant pressure, } \mathrm{kJ} \mathrm{kg}^{-1} \mathrm{~K}^{-1} \\ \mathrm{i} & \text { specific enthalpy, } \mathrm{kJ}_{\mathrm{kg}}{ }^{-1} \\ \mathrm{k} & \text { air specific heats ratio } \\ \mathrm{HRSG} & \text { heat recovery steam generator } \\ \mathrm{NCV} & \text { net calorific value }=42500 \mathrm{~kJ} \mathrm{~kg}^{-1} \\ \mathrm{P} & \text { pressure, } \mathrm{kPa} \\ \mathrm{PR} & \text { pressure ratio }=\mathrm{P}_{2} / \mathrm{P}_{1} \\ \mathrm{PGR} & \text { power gain ratio, Eq. } 19 \\ \dot{Q}_{h} & \text { heat transfer rate, } \mathrm{kW} \\ \dot{m} & \text { mass flow rate, } \mathrm{kg} \mathrm{s}{ }^{-1} \\ \dot{S} & \text { entropy rate }\left(\mathrm{kWK}{ }^{-1}\right) \\ \mathrm{t} & \text { temperature }{ }^{\circ} \mathrm{C} \\ \mathrm{T} & \text { absolute temperature, } \mathrm{K} \\ \mathrm{TEC} & \text { thermal efficiency change, Eq. } 20 \\ \dot{W} & \text { power, } \mathrm{kW} \\ y & \text { is the steam injection ratio }=\dot{m}_{i s} / \dot{m}_{a}\end{array}$

\section{Greek Symbols}

$\begin{array}{ll}\eta & \text { efficiency } \\ \varepsilon_{\text {evc }} & \text { evaporative cooler effectiveness } \\ \xi_{T} & \text { temperature ratio } t_{1} / t_{o} \\ \xi_{T A} & \text { actual temperature ratio } t_{\overline{1}} / t_{o} \\ \dot{\Pi} & \text { entropy generation rate in the control region }\end{array}$

\section{Subscripts}

$\begin{array}{ll}\text { o } & \text { ambient } \\ \text { a } & \text { dry air } \\ \text { c } & \text { compressor } \\ \text { cy } & \text { cycle }\end{array}$

$\begin{array}{ll}\text { e } & \text { evaporator } \\ \text { evc } & \text { evaporative cooler } \\ \mathrm{f} & \text { fuel } \\ \mathrm{fg} & \text { latent heat } \\ \mathrm{h} & \text { heat } \\ \text { is } & \text { injected steam } \\ \text { rev } & \text { reversible } \\ \mathrm{t} & \text { turbine } \\ \mathrm{v} & \text { water vapor }\end{array}$

\section{References}

[1] Alhazmy, M. M., and Najjar, Y. S. H. 2004. Augmentation of gas turbine performance using air coolers, App. Thermal Engineering, Vol. 24, pp 415-429.

[2] Cortes, C. P. E., and Willems, D. 2003. Gas turbine inlet cooling techniques,: An overview of current technology, Proceedings Power GEN 2003, Las Vegas Nevada Dec. 9-11.

[3] Darmadhikari, S., Andrepont, J. S., 2004, Boost gas turbine performance by inlet air cooling, J. Hydrocarbon Processing. Vol. 83 (2), pp 77-86.

[4] Huang, Y. C., Hung, C. I. and Chen C. K. 2000. Exergy analysis for a combined system of steam-injected gas turbine cogeneration and multiple- effect evaporation. J. of power and Energy, IMechI, Vol 214, pp 61-73.

[5] Jassim, R. K. Zaki, G. M. and Alhazmy, M. M. "Energy and exergy analysis of reverse brayton refrigerator for gas turbine power boosting, Chapter 4: Efficiency, Performance and Robustness of Gas Turbines", pp 97-121 (2012).

[6] Korakianities, T. and Wilson, D. G. 1994. Models for predicting the performance of Brayton-cycle engines, Engineering for gas Turbine and Power. Vol. 116, pp 381-388

[7] Ameri, M., Nabati, H. Keshtgar, A., 2004, Gas turbine power augmentation using fog inlet cooling system, Proceedings ESDA04 $7^{\text {th }}$ Biennial conf. engineering systems design and analysis, paper ESDA2004-58101, Manchester, UK.

[8] K. A. Klein, and F. L. Alvarado, EES, Engineering equation solver (2007), Version 7.933, F-Chart Software, WI. USA.

[9] Dossat, R. J., Principles of Refrigeration, John Wiley and Sons, NY. 1997.

[10] Almutairi A., Pilidis P. and Al-Mutawa N. Energetic and Exergetic Analysis of Combined Cycle Power Planr: Part 1 Operation and Performance. Energies 2015, 8, 14118-11135.

[11] Mc Quiston, F. C. Parker, J. D. Spilter, J. D. 2000. Heating, Ventilating and Air conditioning: Design and analysis, $5^{\text {th }}$ edition, John Wily, NY.

[12] Kam, W. Li, and Priddy, A. P. 1985. Power plant system design. John Wiley \& Sons, NY, USA. 